\title{
The Synthesis and Storage Sites of Phenolic Compounds in the Root and Rhizome of Echinacea purpurea
}

\author{
Zengqi Li ${ }^{1}$, Tiexin Tang ${ }^{2}$, Shejian Liang ${ }^{1}$, Xiping Ning ${ }^{1}$, Mei Bai ${ }^{1}$, Hong $\mathrm{Wu}^{1 *}$ \\ ${ }^{1}$ State Key Laboratory for Conservation and Utilization of Subtropical Agro-Bioresources, South China Agricultural University, \\ Guangzhou, China; ${ }^{2}$ School of Pharmaceutical Sciences, Sun Yat-sen University, Guangzhou, China. \\ Email: wh@scau.edu.cn
}

Received January $12^{\text {th }}, 2012$; revised February $17^{\text {th }}, 2012$; accepted March $1^{\text {st }}, 2012$

\begin{abstract}
Cichoric acid is the main phenolic compound in the root and rhizome of the medicinal part, Echinacea purpurea that is known for possessing immune enhancing characteristics. In this study, we analysis the the synthesis and storage sites of phenolic compound in E. purpurea. We used fluorescent microscopy, transmission electron microscopy, cytochemical and immunocytochemical localization to observe the distribution of phenolic compounds. Our results show that the phenolic compounds were mostly distributed in the cortex parenchyma cells, vascular parenchyma cells and pith parenchyma cells in the root and rhizome, and mainly present in the vacuoles, large intercellular spaces and their surrounding cell walls. No phenolic compounds were observed in the cytoplasm and the organelles. We concluded that the phenolic compounds were synthetized in the cortex parenchyma cells, vascular parenchyma cells and pith parenchyma cells in the root and rhizome, and stored in the vacuoles of parenchyma cells. The above results provided significantly cytological information for further approaching the metabolic regulation and transfer pathways of phenolic compounds in biochemistry and molecular biology.
\end{abstract}

Keywords: Echinacea purpurea; Cytochemical Localization; Immunocytochemical Localization; Phenolic Compounds; Root and Rhizome

\section{Introduction}

Echinacea purpurea (L.) Moench. (Compositae) is a perennial herb native to North America. It is widely used in western countries and is a widely recognized immune enhancing herb, with anti-inflammatory, antivirus, and antitumor activity [1-4]. Its main active constituents are caffeic acid derivatives, alkylamide and polysaccharides $[5,6]$. Cichoric acid is the most abundant phenolic compound in the root and rhizome of E. purpurea, and is the important characteristic and immune active constituent $[7,8]$. And it was reported to have HIV-1 and HIV-1 integrase inhibiting effect [9]. The root and rhizome is the medicinal valued portion of E. purpurea, and its biological yield and cichoric acid content are enhanced by optimization of cultivation management, post-harvest and extraction [10-13]. A report of [14] showed that the phenolic compounds mainly present in the parenchyma cells of cortex and phloem, as well as in the pith. But a comprehensive study of its synthesis and storage sites is lacking. We resorted to fluorescent microscopic, cytochemical and immunocytochemical localization techniques to systematically investigate the distribution and

\footnotetext{
*Corresponding author.
}

storage sites of phenolic compounds in the root and rhizome, and on that basis, the synthesis sites, transfer pathways and the storage sites of the phenolic compouds were discussed. This study provided important cytological information for further dissecting the metabolic regulation and metabolite transfer of phenolic compounds in biochemistry and molecular biology.

\section{Materials and Methods}

\subsection{Materials}

Seeds of E. Purpurea were bought from Easyliving Wildflowers seed company. The seeds were grown in Ningxi teaching and scientific research base of South China Agricultural University. The roots (with rhizome) of E. Purpurea grown for two years were harvested in July, 2010. The base locates in Zengcheng city, Guangdong province, China, at altitude of 26 meters, of $23^{\circ} 14^{\prime} 35^{\prime \prime}$ north latitude and $113^{\circ} 38^{\prime} 18^{\prime \prime}$ east longitude, and the soil $\mathrm{pH}$ is 6.1.

\subsection{Methods}

\subsubsection{Frozen Sections}

The Leica CM1900 cryostat was adjusted to $-22^{\circ} \mathrm{C}$ and 
the root and rhizome specimen of E. Purpurea was rapidly cut down at ambient temperature and fixed on a precooled station, and embedded in the medium (Jung Tissue Freeezing Medium) specific for the cryostat, placed on the quick freeze shelf for five minutes, and then cut to $30 \mu \mathrm{m}$ sections. The sections were mainly for fresh fluorescent histochemical observation.

\subsubsection{Fluorescent Microscopy}

Neu's solution [1\% 2-amino-ethyldiphe-nylborinate (Sigma-Aldrich) absolute methanol solution] was dropped to the fresh sections. After reacting for $30 \mathrm{~s}$, the sections were mounted in $10 \%$ glycerol aqueous solution [15], and observed and photographed by the Leica DMLB microscope with fluorescent device (365 nm utralviolet). Because the cichoric acid was the main phenolic compound in E. purpurea, the standard cichoric acid was used as reference in the experiment.

\subsubsection{Histological Structure Observation}

The root and rhizome of the E. purpurea after flowering was cut and rapidly fixed in a solution of $4 \%$ glutaric dialdehyde mixed with $4 \%$ paraformaldehyde dissolved in $0.1 \mathrm{~mol} / \mathrm{L}$ sodium phosphate buffer ( $\mathrm{pH} 7.2)$ overnight at $4^{\circ} \mathrm{C}$, rinsed with phosphate buffer for three times, postfixed in $2 \%(\mathrm{w} / \mathrm{v})$ osmium tetroxide aqueous solution for $3 \mathrm{~h}$, rinsed with phosphate buffer for three times also, dehydrated in an ethanol series, cleared by propylene oxide and embedded in Epon 812. The specimens were cut to sections of 1 - $2 \mu \mathrm{m}$ thickness by Leica RM2155 microtome. The sections were stained in $0.05 \%$ toluidine blue, mounted in neutral resin, observed and photographed by Leica DMLB microscope.

\subsubsection{Cellular Structure Observation}

The specimen prepared as described in 1.2.3 were cut to 70 - 80 nm sections by Leica EM UC6 microtome. The sections were stained by uranyl acetate and lead citrate for 10 - $15 \mathrm{~min}$, then observed and photographed by FEITecnai 12 transmission electron microscopy.

\subsubsection{Immunocytochemical Localization (Referred to [16] Benhamou and Lafontaine 1995)}

Preparation of immuno-gold probes: $100 \mu \mathrm{g}$ Laccase (from Rhus vernificera, Siama-Aldrich) was mixed with $10 \mathrm{ml}$ colloidal gold solution, and 1\% (v/v) PEG20000 was added to stabilize the gold probe, then the mixture was centrifugated for $60 \mathrm{~min}$ at $12000 \mathrm{rpm}$. The precipitate was resuspended in $0.5 \mathrm{ml} \mathrm{PBS}(\mathrm{pH} 6.0$; contained $0.2 \mathrm{mg} \cdot \mathrm{ml}^{-1}$ PEG20000) and stored at $4^{\circ} \mathrm{C}$ until use.

Cytochemical marker: Ultra-thin sections were prepared as described in 3.2.3 and 2.2.4 (no post-fixed inosmium tetroxide aqueous solution). The sections were picked up by Ni grids and suspended in a drop of PBS-
PEG mixture (pH 6.0, containing $0.2 \mathrm{mg} \cdot \mathrm{ml}^{-1}$ PEG20000) for 5 - $10 \mathrm{~min}$, then transferred to a drop of Laccasecolloidal gold complex in a moist chamber for $30 \mathrm{~min}$ at room temperature. Then the sections were rinsed with PBS solution of $\mathrm{pH} 7.2$ for 2 - 3 times, and rinsed with aseptic water for 3 - 5 times, stained by uranyl acetate and lead citrate individually for 10 - $15 \mathrm{~min}$, then observed and photographed by FEI-Tecnai 12 transmission electron microscope. Colloidal gold solution mixed with $100 \mu \mathrm{g}$ PBS of pH 6.5 was used as control.

\section{Results}

A two-year old root and rhizome of E. purpurea had all characteristics of a secondary structure for accumulating phenolic compounds. The main root was made up of periderm, cortex, secondary phloem, vascular cambium, secondary xylem, primary xylem. The structure of the rhizome resembled that of root (Figure 1(A)), except that it had pith, which occupied about $1 / 4$ of the transverse section of the rhizome. Secretory cavities were conspicuously distributed in most tissues, including the cortex, phloem and xylem of the root and rhizome (Figures $\mathbf{1}(\mathbf{A}),(\mathbf{B}))$, and the pith of the rhizome.

\subsection{Fluorescent Histological Localization of the Phenolic Compounds}

Neu's solution is the standard test solution for localization of phenolic compounds in plants, in which borate will react with the phenolic compounds and form a complex, which will generate fluorescence of special color under certain conditions $[17,18]$. Astandard cichoric acid emits yellow green fluorescence (Figure 1(H)).

The cortex parenchyma cells of a two-year old rhizome treated with Neu's solution (Figure 1(C)) displayed a large amount of yellow green fluorescent spots in the cortex parenchyma cells. When examined with a $100 \times$ objective lens (immersion with Leica low fluorescent cedar oil), the fluorescent substance was distributed in the cell close to the cell wall, and in the form of sphere or lump. They were also visible in large intercellular spaces (Figure 1(E)). Furthermore, fairly strong yellow green fluorescence was seen in phloem parenchyma cells (Figure 1(F)) and xylem parenchyma cells (Figure

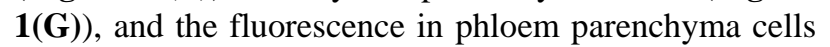
was stronger and the fluorescent substance was distributed in very close proximity to the cell wall. Although the thickened cell wall of the xylem vessels produced pale blue fluorescence, it was actually originated from lignin. The observation of the pith parenchyma cells was similar to that in the cortex (image not presented). Distribution features of the fluorescent substance in the root were generally the same as that of the rhizome (Figure 1(D)), mainly in the cortex parenchyma cells, phloem 


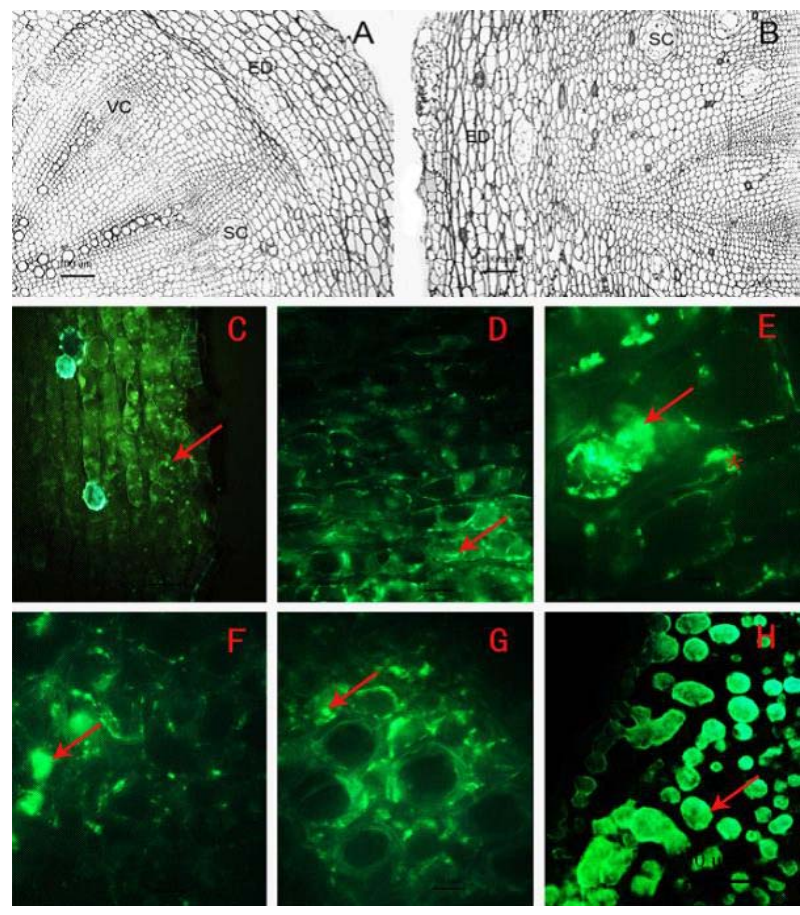

Figure 1. (A), (B) Transverse section of two years old E. purpurea root (A) and rhizome (B). (C)-(H) Fluorescence of phenolic compounds after Neu's treatment (pointed by arrow), (C) cortex of rhizome (D) cortex parenchyma of root (E) cortex parenchyma cells of rhizome (*fluorescence in intercellular spaces) (F) phloem parenchyma cells of rhizome (G) xylem parenchyma cells of rhizome. (H) fluorescence of the cichoric acid standard. ED: peridem, SC: secretory cavity, VC: vascular cambium; Scale: (A), (B), 100

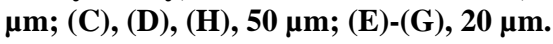

parenchyma cells, and xylem parenchyma cells. By way of comparing with the strong fluorescence resulting from cichoric acid (Sigma) treated with Neu's solution for 30 seconds and lit by $365 \mathrm{~nm}$ ultraviolet light (Figure 1(H)), and through analyzingthe fluorescence strength and color of the histological structure, we concluded that the fluorescent substance in the parenchyma cells was that of phenolic compounds, and most of which was cichoric acid.

Based on results of optical microscopy, the main distribution sites of the phenolic compounds were parenchyma cells of cortex, phloem, xylem and pith, and very little phenolic compounds were distributed in the intercellular spaces of the parenchyma cells.

\subsection{Cytochemical Localization of the Phenolic Compounds}

Because the phenolic compounds would be strongly stained by osmium tetroxide [19], and the product could be easily recognized in a form of aggregates [20], the distribution of the electron opague product from the osmium tetroxide stained phenolic acids in the cells was further examined by electron microscopy.

Under electron microscope, there was light cytoplasm and a typical centric big vacuole in the mature of cortex parenchyma cell of the two-year old rhizome. Alongside the tonoplast, dark osmiophilic droplets of high density were present (Figure 2(A)), mostly spherical in form. Considering the form and distribution features of the fluorescent granules observed by $100 \times$ fluorescent microscope (Figures 1(E)-(G)), it was left with little doubt that the osmiophilic droplets were resulted from phenolic compounds. For simplicity, we herein designate them as phenolic droplets. The phenolic droplets in the rhizome concentrated mostly in the vacuole. They scattered in the vacuole singly or aggregated together. Under higher magnification, a great deal of black flocculent substance was visible in the vacuoles of the cells (Figures 2(B), (C)). The flocculent substance was continuously transferred from the tonoplast into the vacuole and gradually gathered around the phenolic droplets, and contributed to the formation of the droplets. In the cytoplasm around the vacuole, abundant mitochondria were observed (Figure 2(C)).

In the cortex parenchyma cells of the root, the distribution features of the phenolic droplets largely resembled that in rhizome (Figure 2(D)). In the corners of intercellular spaces of the parenchyma cells of the root, pieces of dark osmiophilic droplets were prominant (Figures 2(E), (F)), and their form and electron density were the same as those phenolic droplets in the vacuoles. The small phenolic droplets were also found to occurr in the cell walls surrounding these intercellular spaces (Figures 2(E), (F)). Compared with the fluorescence image in the intercellular spaces of Figure 1(E), the osmiophilic substance should be phenolic compounds also.

The distribution features of the phenolic droplets indicated that most of them were present in the vacuoles, intercellular spaces and the surrounding cell wall. None of them was present in the cytoplasm or organelle. The images we acquired suggested that a great number of black flocculent phenolic droplets were transferred from the tonoplast into the vacuole. But why was it not found in the cytoplasm? We reasoned that the black flocculent phenolic droplets would not be recognized in the cytoplasm or the cytoplasm was not a site of the final synthesis of phenolic compounds. To study that question, immunocytochemical technique was employed to locate the phenolic compounds.

\subsection{Immunocytochemical Localization of the Phenolic Compounds}

Laccase is a polyphenol oxidase, which will catalyze the oxidization of substrates like polyphenols, aromatic polyamines, etc. It will form laccase-gold complex with 


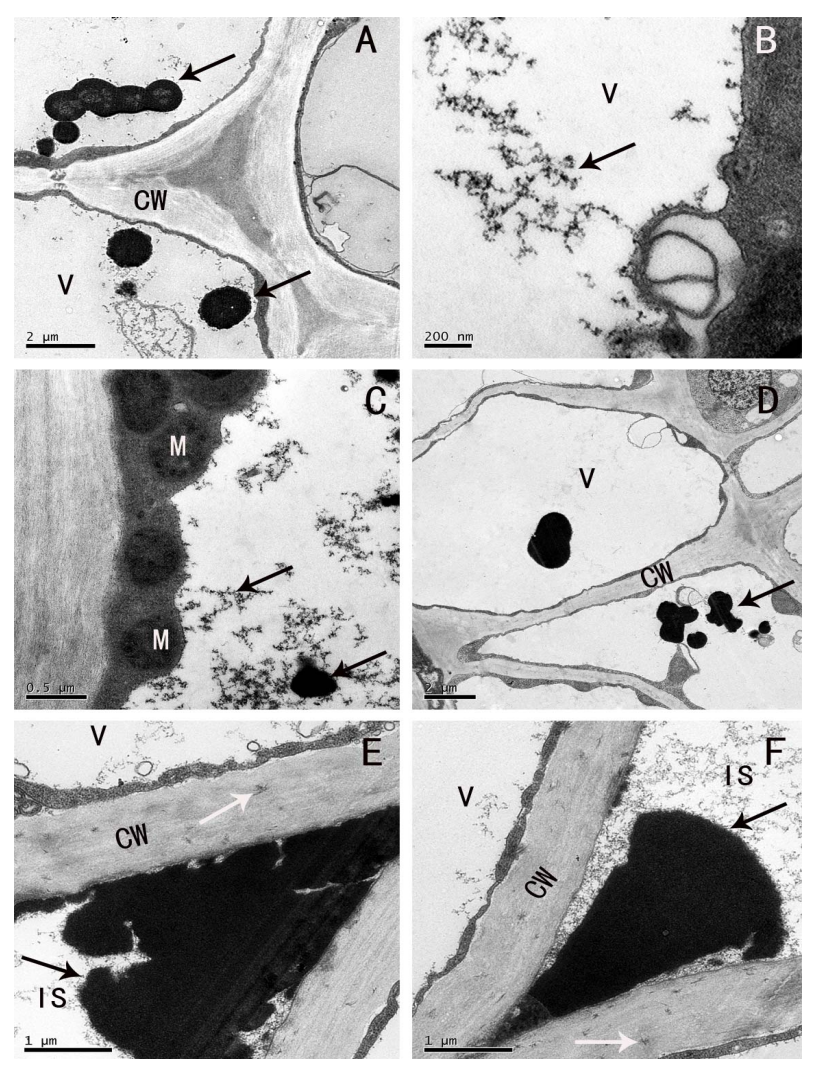

Figure 2. (A)-(F) Cytochemical localization of the phenolic compounds in E. purpurea (A) phenolic droplets in the cortex parenchyma cells of rhizome (arrow), (B), (C) In cortex parenchyma cells of rhizome, flocculent phenolic compounds and big phenolic droplets (black arrow), (D) phenolic droplets in the root parenchyma cells (arrow), (E), (F) phenolic lumps in the intercellular spaces of the root parenchyma cells (black arrow) and flocculent osmiophilic substance on the cell wall (white arrow); CW: cell wall, IS: intercellular space, $M$ : mitochondria, V: vacuole; Scale: (A),

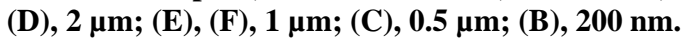

colloidal gold solution and signals the precise localization of phenolic compounds in the cells. The distribution and storage sites of the phenolic compounds could be located by observing the distribution and amount of the gold granules under the transmission electron microscope $[16,21]$.

Observed by the immunocytochemical localization, gold granules were found scattered or gathered in the vacuoles of the parenchyma cells of the rhizome (Figure 3(A)) and root (Figure 3(B)). Generally, the vacuoles were strongly labeled, the gold granules gathered to form lumps in the vacuoles near the cytoplasm (Figures 3(C), (D) Figure 4(A)), and they were seen in the large intercellular spaces and their adjacent cell walls (Figure 4(B)). Few scattered gold granules were found in the control (Figure 4(C)), which were normal phenomena of small amount of residue after colloidal gold treatment. Our results were consistent with those of cytochemical localization of the phenol compounds, and indicated that the flocculent dark osmiophilic substance and spherical dark droplets in electron microscope, the yellow green fluorescent granules in the fluorescent microscope were all phenolic compounds.

Also, no gold labeling was found in the cytoplasm, peroxisomes and mitochondria (Figure 4(D)), Golgi apparatus (image not presented), and nucleus (Figures 3(A), (B)). But labeling was found in some plastids that contained starch grains. The gold granules mostly distributed around or on the starch grains (image not presented).

Immunocytochemical localization results indicated that the cytoplasm was not the site for the synthesis of the final phenols compounds.

\section{Conclusion and Discussion}

\subsection{Synthesis and Storage Sites of Phenolic Compounds}

Study for distribution, synthesis site, transfer pathway and storage site of the medicinal constituents in the medicinal plant will provide scientific basis for the identification of medicinal materials and selection of optimal harvest time, optimal storage method and optimal extraction method of

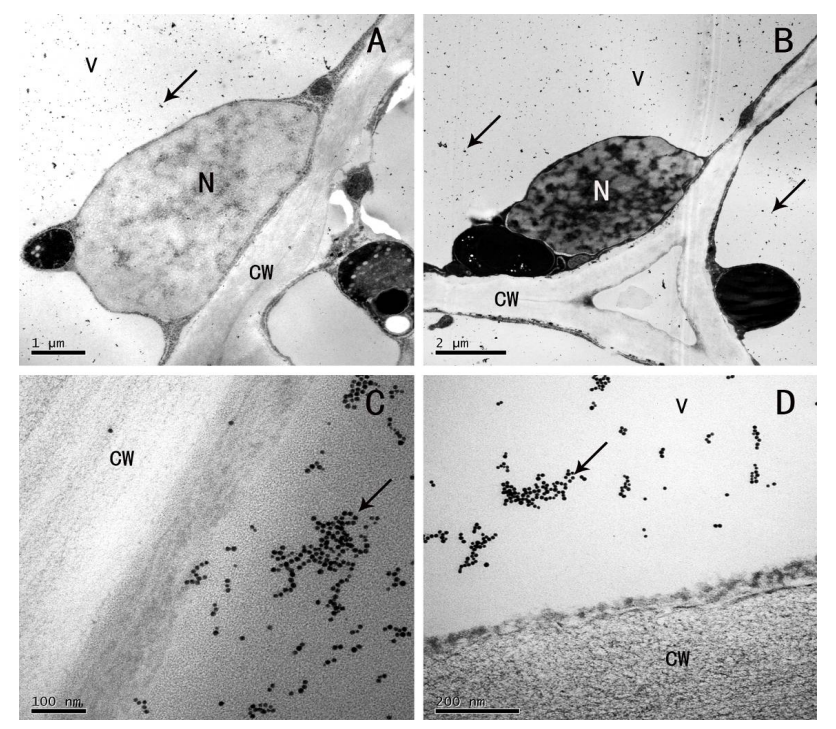

Figure 3. (A)-(D) Immunogold localization of phenolic compounds (A) contents in vacuole of the parenchyma cells of rhizome were strongly labeled (arrow), few gold granules were scattered in the cell wall and nucleus (might be the residue in wash procedure of the experiment), (B) distribution of gold granules in root parenchyma cells, contents in vacuole were strongly labeled (arrow), little labeling in intercellular space, no labeling on cell wall (black spots of uniform size in the vacuole, arrow), (C), (D) distribution of gold granules in the vacuoles near the cell wall (arrow). CW: cell wall, $\mathrm{V}$ : vacuole, $\mathrm{M}$ : mitochondria, $\mathrm{N}$ : nucleolus, PO:

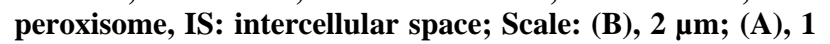
$\mu \mathrm{m}$; (C) $100 \mathrm{~nm}$; (D), $200 \mathrm{~nm}$. 


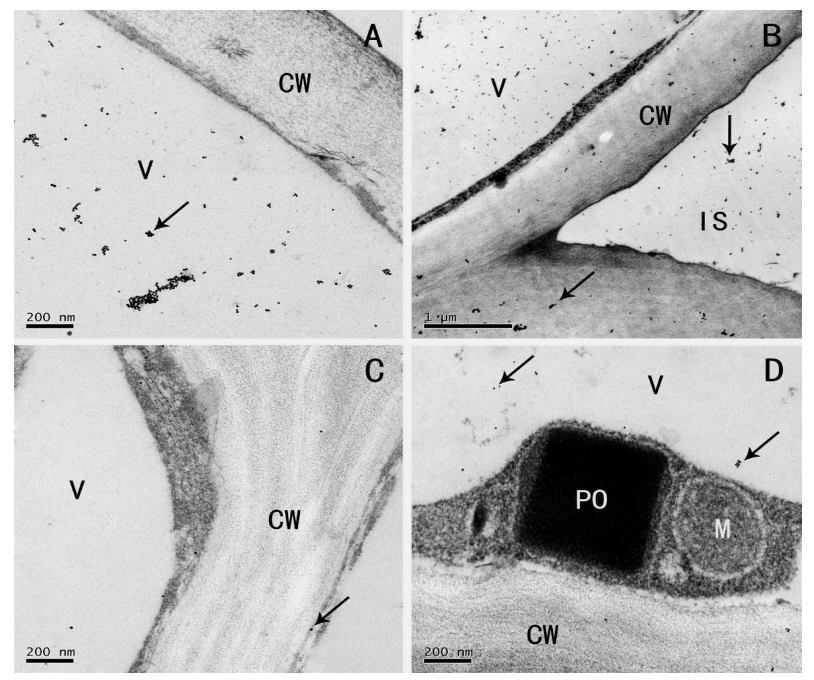

Figure 4. (A)-(D) Immunogold localization of phenolic compounds (A) distribution of gold granules in the vacuoles near the cell wall (arrow), (B) gold granules in the big intercellular spaces and their surrounding cell walls (arrow), (C) colloidal gold solution without Laccase as control, (D) no colloidal gold labeling in peroxisomes and mitochondria. CW: cell wall, V: vacuole, $M$ : mitochondria, PO: peroxisome, IS: intercellular space; Scale: (B), 1 um; (A), (C), (D), $200 \mathrm{~nm}$.

active constituents. Histochemical localization technique is an effective means to find out the distribution and accumulation patterns of medicinal constituents in organs and tissues [22]. But histochemical techniques commonly show only the distribution of the active constituents in medicinal plant. So studying the synthesis and accumulation sites of the active constituents in cells will require a combination of histochemical and immunocytochemical methods so as to provide more direct cytological evidence for testifying the metabolic mechanism.

With the Hoepfner-Vorsatz reaction treatment, [14] found that the phenolic compounds were mainly distributed in the cortex, phloem parenchyma cells, vascular ray, and pith in Echinacea purpurea. To further investigate the distribution and storage sites of the phenolic compounds, Neu's solution was used to detect the phenolic compounds. The reacting product emitted special fluorescence under the ultraviolet light and showed the distribution of the phenolic compounds. It was found that the fluorescence of the phenolic compounds was present in the parenchyma cells of both the root and the rhizome, and the main locations was generally consisted with the results the previous report [14]. Aided by a $100 \times$ oil immersion lens, we revealed that the phenolic compounds were in the parenchyma cells, both in spots and lumps, and occasionally in the intercellular spaces as well (Figure 1(E)). To further study the distribution features at a ultracellular structural level, and based on the property that phenolic compounds are strongly stained by osmium tetroxide, we used electron microscope to show that black high electron density substance were formed spheres and lumps in the vacuoles (Figures 2(A), (D)), and intercellular spaces (Figures 2(E), (F)). Some black flocculent substance was found on the cell wall, but only at sites surrounding large intercellular space. Because lipids in the cell are also osmiophilic, it is difficult to differentiate them from the phenolic compounds, but immunocytological localization techniques revealed that cell wall was the distribution sites of phenolic compounds $[16,23]$. Therefore, laccase-colloidal gold labeling was used to locate the phenolic compounds in the cells. Our results showed that a large number of gold granules gathered in and alongside the vacuoles in the parenchyma cells (Figures 3(A)-(D), 4(A)). A small number of them were in the intercellular spaces and on their surrounding cell wall (Figure 4(B)). Taken together, we concluded that the phenolic compounds were mainly distributed in the cortex parenchyma cells, vascular parenchyma cells, and pith, and the vacuoles were an important storage sites, while the intercellular spaces were the auxiliary storage sites in apoplast.

\subsection{Synthesis and Transfer of the Phenolic Compounds}

The phenolic compounds in higher plants are synthesized via shikimate pathway. Phenylalanine ammonia-lyase (PAL), cinnamate-4-hydroxylase (C4H), and 4-coumarate: coenzyme A ligase (4CL) were three key enzymes influencing that pathway $[24,25]$, and the PAL and C4H were the two key enzymes closely related to the synthesis of phenolic compounds. PAL is the key and rate-limiting enzyme in shikimate pathway, and is the key factor influencing the accumulative level of the phenolic compounds [26]. On a histological level, PAL was mainly located in the subepidermal cells and vascular parenchyma cells in plants, but on a subcellular level it was in the cytoplasm [27], some organelles including chloroplasts, leucoplasts, mitochondria, peroxisomes, and glyoxysomes [28], and the Golgi apparatus vesicles and thickened layer of secondary cell wall [27]. C4H was located in certain areas of the chloroplast (plastid) and nucleus [29]. [20] studied the phenolic compounds storage in the parenchyma cells of Picea abies (Norway spruce) cortex with PAL localization and found that PAL was in the cell membrane and tonoplast, and mainly distributed alongside the cell membrane, but not in the cell wall, vacuole, and other membrane organelles. Therefore, PAL distributions are apparently very diverse in different plants.

In this study, observations at the cytological level revealed that in the parenchyma cell of E. purpurea storing phenolic compounds, the phenolic droplets initially formed 
small particles on the inner membrane of vacuoles, then gradually diffused into the vacuoles and gathered to form larger spheres. At the same time, black phenolic droplets were found on the cell wall outside the cytoplasm membrane. Although abundant mitochondria, peroxisomes, etc. were present in the cytoplasm, no phenolic droplets were observed in the cytoplasm and those organelles. The immunocytochemical loalization results showed that the vacuole constituents were strongly labeled, while the cytoplasm was not, and the big cellular spaces and their surrounding cell walls were labeled but not as strong as the vacuoles. Peroxisomes, Golgi apparatus and mitochondria were not labeled. Few plastids were labeled, only those containing starch grains were marked with some gold granules, and the gold granules gathered around the starch grains or directly on the starch grains. These results were consistent with the immune gold labeling results of polyphenols in rhizome of Polypodium vulgare L. studied by [23]. As to the partial labeling of the starch grains, its reason is not yet clear.

Based on our results as a whole and taking into account of current literature, we propose that in the cytoplasm and membrane organelles (mainly peroxisomes and mitochondria), only the precursors of phenolic compounds were synthesized, as they would not be fixed by osimic acid or react with the Laccase. the precursors enter the vacuoles by active transport energized by mitochondria, and at the same time, are converted to the phenolic compounds by specific enzymes in the tonoplast. The phenolic compounds gradually gathered to form bigger spherical phenolic droplets in vacuoles and stored. The enzymes converting the precursors to phenolic compound were not only present in the tonoplast, but also in the cell membrane. The precursor were converted by the enzymes in the cell membrane and the product was transported to outside the membrane, through the cell wall and accumulated in the intercellular spaces. Further cytological and biochemical study is needed to delineate the enzymes in the tonoplast and cell membrane performing the biochemical conversions.

\subsection{The Protective Effect of the Phenolic Compounds}

To resist the attack from herbivores and pathogens, a complex defense mechanism is formed in plants, and the root systems of plants play important role in this process. Commonly, the parenchyma cells of plants will actively synthesize, store and modify phenolic substances, and release the stored phenolic compounds to perform their protective effect when plant gets encounter attacks [20, 30] (Franceschi et al. 1998, 2000). Plenty of phenolic compounds are stored in the vacuoles of parenchyma cells of the E. purpurea root and rhizome, it will im- proved themself protective effect, especially inhibit herbivores utilization rate of protein, enzyme activity, integrity maintaining of the cell membrane, etc. [31].

In addition, [16] used Laccase-colloidal gold localization to study the tomato root infected by Fusarium oxysporum f.sp. radicis-lycopersici, and found that the phenolic compounds were in the cell wall and intercellular spaces of the host and considered that the intercellular phenolic compounds would interact with the cell membrane of the fungi and inhibit the growth of fungal filament and degrade them. And the phenolic compounds in the cell wall of the host would prevent the fungal filament from invasion. With our cytochemical localization and immunogold labelling results that black phenolic droplets or gold granules were in the big intercellular spaces and the surrounding cell walls (Figure 4(B)), it was speculated that the phenolic compounds might go through the cell wall, and store in the intercellualar spaces outside the cell, inhibit the pathogens invading from the apoplast pathway and start the first defence barrier in time after the plant was harmed or infected. As to the abundant phenolic compounds in the vascular parenchya cells, it might perform important protective effect on preventing the pathogen from spreading via vessels and guaranteeing the normal transportation of the nutrients in the phloem.

\section{Acknowledgements}

We thank Dr. Jitao Zou for critically reading the manuscript. This work was supported by grants from the Funds for Industry-University-Research Cooperation from the Guang-dong Provincial Government and the Ministry of Education of the PR China (2008B090500250) and Science and Technology Planning Project of Guangdong Province, China (2011B031700026) for financial support.

\section{REFERENCES}

[1] M. Stimel, A. Proksch and H. Wagner, "Macrophage Activation and Induction of Macrophase Cytotoxicity by Purified Polysaccharide Fractions from the Plant Echinacea purpurea," Infection and Immunity, Vol. 46, No. 3, 1984, pp. 845-854.

[2] H. Wagner, "Immunologically Active Polysaccharides of Echinacea purpurea Cell Cultures,” Phytochemistry, Vol. 27, No. 1, 1988, pp. 119-126. doi:10.1016/0031-9422(88)80601-0

[3] R. Bauer and H. Wagner, "Echinacea Species as Potential Immunostimulatory Drugs,” Economic and Medicinal Plant Research, Vol. 5, 1997, pp. 253-321.

[4] G. Vinti, C. Chuck, V. S. Jan, R. Barton, R. Bauer, R. Gahler and T. K. Basu, "Alkylamides of Echinacea purpurcea Stimulate Alveolar Macrophage Function in Nor- 
mal Rats,” Internationnal Immunopharmacology, Vol. 2, No. 1-2, 2002, pp. 381-387.

[5] F. J. Reith, "Pharmaceuticals Containing Lactic Acid Derivatives and Echinacea," Bundesrepublik Deutsches Patentamt, Vol. 2, 1978, pp. 721-731.

[6] A. Wacker and W. Hilbig, "Virushemmung Mit Echinacea purpurea," Planta Medica, Vol. 33, No. 1, 1978, pp. 89-102. doi:10.1055/s-0028-1097364

[7] H. Soicke, G. A. I-Hassan and K. Gorler, "Weitere Kaffeesaure Derivate aus Echinacea purpurea," Planta Medica, Vol. 54, No. 2, 1988, p. 175.

[8] N. B. Perry, E. J. Burgess and V. A. Glennie, "Echinacea Standardization: Analytical Methods for Phenolic Compounds and Typical Levels in Medicinal Species,” Journal of Agricultural and Food Chemistry, Vol. 49, No. 4, 2001, pp. 1702-1706. doi:10.1021/jf001331y

[9] W. E.-J. Robinson, "L-Chicoric Acid, a Dicaffeoyltaric Acid Inhibitor of HIV Integrase, Improves on the in Vitro Anti-HIV Effect of Zidovudine and a Protease Inhibitor (AG1350),” Antivitral Research, Vol. 39, No. 2, 1998, pp. 101-111.

[10] R. Chen, H. Nian and H. Wu, "Effect of Nitrogen, Phosphorus, and Potassium on Yield and Quality of Echinacea purpurea," Chinese Traditional and Herbal Drugs, Vol. 38, No. 6, 2007, pp. 917-920.

[11] R. Chen and H. Wu, "Influence of Microfertilizers on Yield and Seed Production of Echinacea Purpurea," Chinese Traditional and Herbal Drugs, Vol. 38, No. 9, 2007, pp. 1400-1403.

[12] H. O. Kim, T. D. Durance, C. H. Scaman and D. D. Kitts, "Retention of Cichoric Acid Derivatives in Dried Echinacea purpurea," Journal of Agricultural Food and Chemistry, Vol. 48, No. 9, 2000, pp. 4182-4186. doi:10.1021/jf000245v

[13] Y. L. Zhang, T. X. Tang, H. J. He, H. Wu and Z. Y. Hu, "Influence of Several Postharvest Processing Methods on Polyphenoloxidase Activity and Cichoricacid Content of Echinacea purpurea Roots," Industrial Crops and Products, Vol. 34, No. 1, 2011, pp. 873-881. doi:10.1016/j.indcrop.2011.02.010

[14] P. Li, X. P. Ning and H. Wu, "Relationship between Structure of Medicinal Fractions and Accumulation of Polyphenol in Echinacea purpurea," Chinese Traditional and Herbal Drugs, Vol. 38, No. 4, 2007, pp. 606-610.

[15] G. H. Dai, C. Andary, L. Mondolot-Cosson and D. Boubals, "Involvement of Phenolic Compounds in the Resistance of Grapevine Callus to Downy Mildew (Plasmopara viticola)," European Journal of Plant Pathology, Vol. 101, No. 5, 1995, pp. 541-547. doi:10.1007/BF01874479

[16] N. Benhamou and P. J. Lafontaine, "Ultrastructural and Cytochemical Characterization of Elicitor-Induced Structural Responses in Tomato Root Tissues Infected by Fusarium oxysporum f. sp. radicis-lycopersici," Planta, Vol. 197, No. 1, 1995, pp. 89-102. doi:10.1007/BF00239944

[17] C. Valette, C. Andary, J. P. Geiger, J. L. Sarah and M. Nicole, "Histochemical and Cytochemical Investigations of Phenols in Roots of Banana Infected by the Burrowing Nematode Radopholus similis,” Phytopathology, Vol. 88, No. 11, 1998, pp. 1141-1148. doi:10.1094/PHYTO.1998.88.11.1141

[18] L. Mondolot, P. L. Fisca, B. Buatois, E. Talansier, A. Kochko and C. Campa, "Evolution in Caffeoylquinic Acid Content and Histolocalization during Coffea Canephora Leaf Development," Annals of Botany, Vol. 98, No. 1, 2006, pp. 33-40. doi:10.1093/aob/mcl080

[19] R. A. Parham and H. M. Kaustinen, "Differential Staining of Tannin in Sections of Epoxy-Embedded Plant Cells," Stain Technology, Vol. 51, No. 4, 1976, pp. 237-240.

[20] V. R. Franceschi, T. Krekling, A. A. Berryman and E. Christiansen, "Specialized Phloem Parenchyma Cells in Norway Spruce (Pinaceae) Bark Are an Important Site of Defense Reactions,” American Journal of Botany, Vol. 85, No. 5, 1998, pp. 601-615. doi:10.2307/2446529

[21] J. P. Geiger, B. Rio, D. Nandris and M. Nicole, "Laccases of Rigidoporus lignosus and Phellinus noxius, I. Purification and Some Physicochemical Properties,” Applied Biochemistry Biotechnology, Vol. 12, No. 2, 1986, pp. 121133. doi:10.1007/BF02798419

[22] S. B. Liu, H. M. Liao and Z. H. Hu, "Correlation Studies on the Structure and the Contents of Gypenosides in Vegetative Organs of Gynostemma pentaphyllum in Different Developmental Stages,” Journal of Wuhan Botanical Research, Vol. 23, No. 2, 2005, pp. 144-148.

[23] A. Bagniewska-Zadworna, E. Zenkteler, P. Karolewski and M. Zadworny, "Phenolic Compound Localisation in Polypodium vulgare L. Rhizomes after Mannitol-Induced Dehydration and Controlled Desiccation," Plant Cell Reports, Vol. 27, No. 7, 2008, pp. 1251-1259. doi:10.1007/s00299-008-0548-3

[24] B. Weisshaar and G. I. Jenkins, "Phenylpropanoid Biosynthesis and Its Regulation," Current Opinion in Plant Biology, Vol. 1, No. 3, 1998, pp. 251-257. doi:10.1016/S1369-5266(98)80113-1

[25] W. S. Brenda, "Evidence for Enzyme Complexes in the Phenylpropanoid and Flavonoid Pathways,” Physiologia Plantarum, Vol. 107, No. 1, 1999, pp. 142-149. doi:10.1034/j.1399-3054.1999.100119.x

[26] B. S. Bushman, M. E. Snood, M. E. Snook, J. P. Gerke and S. J. Szalma, "Tow Loci Exert Major Effects on Chorogenic Acid Synthesis in Maize Silks,” Crop Science, Vol. 42, No. 5, 2002, pp. 1669-1670. doi:10.2135/cropsci2002.1669

[27] J. Nakashima, T. Awano, K. Takabe, M. Fujita and H. Saiki, "Immunocytoochemical Localization of Phenylalanine ammonia-lyase and Cinnamyl Alcohol Dehydrogenase in Differentiating Tracheary Elements Derived from Zinnia mesophyll Cells,” Plant and Cell Physiology, Vol. 38, No. 2, 1997, pp. 113-123.

[28] K. R. Hanson and E. A. Havir, "Phenylalanine ammonialyase: A Model for the Cooperativity Kinetics Induced by D-and L-phenylalanine,” Archives of Biochemistry and Biophysics, Vol. 211, No. 2, 1981, pp. 564-574. doi:10.1016/0003-9861(81)90491-4

[29] J. Y. Chen, P. F. Wen, W, F, Kong, Q. H. Pan, S. B. Wan 
and W. D. Huang, "Changes and Subcellular Localizations of the Enzymes Involved in Phenylpropanoid Metabolism during Grape Berry Development,” Journal of Plant Physiology, Vol. 163, No. 2, 2006, pp. 115-127. doi:10.1016/j.jplph.2005.07.006

[30] V. R. Franceschi, P. Krokene, T. Krekling and E. Christiansen, "Phloem Parenchyma Cells Are Involved in Local and Distant Defense Responses to Fungal Inoculation or Bark-Beetle Attack in Norway Spruce (Pinaceae), American Journal of Botany, Vol. 87, No. 3, 2000, pp. 314-326. doi:10.2307/2656627

[31] R. L. Lindroth and G. O. Batzli, "Plant Phenolics as Chemical Defenses: Effects of Natural Phenolics on Survival and Growth of Prairie Voles (Microtus ochrogaster)," Journal of Chemical Ecology, Vol. 10, No. 2, 1984, pp. 229-244. doi:10.1007/BF00987851 